\title{
ORFEU E EURÍDICE: AMANTES DIABÓLICOS CRIADORES DE UMA PSEUDOPOESIA MODERNA
}

Fernanda Verdasca Botton

Professora de Teoria Literária UniABC
RESUMO: Escrita pelo dramaturgo português Bernardo Santareno, a peça teatral $O$ inferno tem como personagens principais um casal de assassinos em série denominados como Orfeu e Eurídice. Este trabalho tem por objetivo refletir sobre o uso dos nomes mitológicos no texto do escritor português.

PALAVRAS-CHAVE: Literatura; Mito; Poesia; Modernismo; Nazismo.

ORFEU E EURÍDICE:

AMANTES DIABÓLICOS CRIADORES DE UMA PSEUDOPOESIA MODERNA

ABSTRACT: Composed by the portuguese playwright Bernardo Santareno, the play $O$ Inferno has as its mains characteres a cople of mass murderes, nameds as Orfeu and Euridice. This study aims to examine the use of mythological names in the text of the Portuguese writer.

KEYWORDS: Literature; Myth; Poetry; Modernism; Naziism. 
No ano de 1967, Bernardo Santareno traz a lume a peça teatral O inferno. No écran inicial do texto em questão, o autor esclarece que o enredo é baseado no verdadeiro julgamento dos assassinos seriais Ian Brady e Myra Hindley. Contudo, apesar de ter como ponto de partida um fato real ocorrido na Inglaterra, o dramaturgo português opta por designar suas personagens principais não pelo nome dos verdadeiros assassinos, mas sim pelo nome dos amantes míticos Orfeu e Eurídice.

Assassinos atrozes de duas crianças e um adolescente, Orfeu e Eurídice santarenianos escolhem suas vítimas segundo a filosofia da raça ariana pregada por Hitler. A judia Ann Gilbert, tinha apenas dez anos quando foi estuprada e estrangulada pelo casal. John Huston, um menino de doze anos que possuía a tez negra, foi a segunda vítima dos assassinos. Edward Jones teve seu crânio brutalmente atingido por golpes de machado e, mesmo depois de morto, recebeu pontapés e golpes de "stick" ao som dos gritos de Orfeu que acusavam o adolescente de 17 anos de ser homossexual.

Com o intuito de refletirmos o motivo que levou Santareno a denominar suas personagens com os nomes mitológicos de Orfeu e Eurídice, dividiremos nosso estudo em duas partes. Na primeira, cotejaremos o mito amoroso de Orfeu e Eurídice com a história dos assassinos criados pelo dramaturgo português. Na segunda, a pertinência dos assassinos declamarem, como pseudopoetas modernos, à beira dos túmulos de suas vítimas, os versos da lâmina órfico-dionisíaca Petelia.

Na reportagem do jornal português Diário de Notícias, os assassinos seriais foram designados como "os amantes diabólicos de Chester" e esse seria, inicialmente, o motivo que fez com que Santareno os designasse em sua peça como os amantes míticos Orfeu e Eurídice. Contudo, outros elementos do enredo acrescentariam à compreensão do cotejo realizado pelo dramaturgo português.

Em $O$ inferno, a relação amorosa entre Orfeu e Eurídice tem início em um escritório. Como executivo, Orfeu entrevista mulheres para o cargo de secretária. Uma delas diz que o pai de suas duas filhas "desapareceu no nevoeiro" (SANTARENO, s.d., p. 201). Após Orfeu escarnecer dessa primeira mulher, ele recebe a segunda "sem se voltar" (ibidem, p.204), mas a encara bruscamente quando ouve seu nome, Eurídice. Fazendo então reverência àquela que seria sua amada eterna, Orfeu deseja que Eurídice seja "bem-vinda ao inferno" (ibidem, p.205). 
O nevoeiro, os olhos a se encontrarem e a morada infernal são referências que Santareno faz aos elementos de um dos mais conhecidos mitos a falar da separação que causa o sofrimento lírico amoroso, o mito de Orfeu e Eurídice. Podemos encontrar essas referências nas palavras que Bernadette Bricout escolheu para resumir esse mito:

Orfeu, descido aos Infernos para buscar Eurídice, toca as cordas de sua lira. Com seu canto, emociona Plutão e Prosérpina, os seres incorpóreos e a própria noite. Consegue que lhe seja devolvida aquela que a morte lhe tirara, sob a condição de não se voltar para ela antes de tê-la trazido para a luz do dia. Ele a precede, portanto, no estreito caminho envolvido em espesso nevoeiro mas, uma vez à beira do mundo, cede à impaciência de rever o seu rosto. Eurídice é imediatamente sugada pelo abismo, onde se desfaz como fumaça. (BRICOUT, 2003, p. 13).

O trecho acima comprova que as referências utilizadas por Santareno evocam o mito amoroso de Orfeu e Eurídice. Contudo, se compararmos esse mito com a situação criada pelo autor, podemos perceber um dramaturgo que realiza um texto paródico, uma vez que os elementos citados formam um canto contrário ao mito original.

Atribuindo à primeira mulher um certo ar amargo, Santareno a coloca como uma pessoa a ironizar o sentimento amoroso: em meio ao nevoeiro espesso, o amado não a guiou para o mundo da luz, mas sim a abandonou sem dinheiro e com dois filhos para sustentar.

Eurídice, por sua vez, encontrará no nome de seu futuro chefe referência à história mítica do amor eterno. Todavia, no texto santareniano, o canto de sofrimento entoado por uma separação passa a ser uma melodia em que um Orfeu olha para sua Eurídice com o intuito de trazê-la não ao mundo da luz, mas sim ao sítio infernal de uma vida em que habitam a violência assassina e a sexualidade desmedida.

Importante acrescentarmos que a história do amor absoluto de Orfeu por Eurídice e da separação eterna do casal é um tema lírico perpetuado por vários poetas. Salientamos, contudo, que o canto inebriante de Orfeu já existia antes dele ter se apaixonado por Eurídice.

Edith Hamilton, por exemplo, observa que antes de conhecer a bela amada, “Orfeu, ao tanger a sua lira melodiosa, arrastava as árvores (e) conduzia os animais selvagens da floresta" (HAMILTON, 1983, p. 147). Além disso, acrescenta a autora, no argo de Jasão, o som da lira de Orfeu foi capaz de salvar os argonautas do canto de morte das sereias. 
Édouard Schuré, por sua vez, observa que antes de cantar o sofrimento pela perda da amada, a música de Orfeu serviu para salvar Eurídice das mãos da sacerdotisa infernal Aglaonice. Essa visão de Schuré nos interessa particularmente, pois esse escritor francês traz à obra Les Grands Initiés (1889) um Orfeu responsável por um canto que salva os "homens desgraços" (SCHURÉ, 2003, p. 59), inclusive Eurídice, dos erros cometidos em suas "milhares de existências" (ibidem, loc. cit.).

As idéias de Schuré nos guiam à segunda parte de nossa discussão: compreender o motivo que levou "os amantes diabólicos de Chester" a entoarem o canto da lâmina Petelia, à beira da cova de suas vítimas.

Na mitologia grega, nascido de Apolo e da Musa Calíope, Orfeu teria recebido dos pais o dom do canto. Na adolescência, esse dom fora aperfeiçoado quando ele, em uma viagem ao Egito, recebera dos sacerdotes de Mênfís a revelação dos "Mistérios da alma”. Nesse momento, seu nome passou a revelar uma missão a ser cumprida: a de curar pela luz ${ }^{1}$. Contudo, tendo sofrido com a morte prematura de sua mãe, Orfeu teria abandonado essa sua missão ao descer do templo dos deuses para habitar nos vales tenebrosos da terra.

A sacerdotisa Aglaonice reinava nesses vales quando Orfeu a eles chegou. Em nome do poder infernal de Hécate, Aglaonice queria conquistar a bela virgem Eurídice e torná-la mais uma de suas bacantes. Entretanto, os objetivos da sacerdotisa seriam frustrados quando Orfeu, encantado pela beleza de Eurídice, por essa se apaixonou e decidiu levá-la ao himeneu. Aglaonice, por sua vez, não aceitou perder Eurídice e preparou para ela um veneno mortal que levou a noiva à morte súbita. Nesse momento, Orfeu narra seu desespero:

Quando eu vi a fogueira consumir Eurídice, quando eu vi o túmulo devorar as suas cinzas, quando a última recordação da sua forma viva desapareceu, então eu gritei: 'Onde está a sua alma?' E parti desesperado. Depois, errei por toda a Grécia. (...) Finalmente, cheguei ao antro de Trofônio, onde certos sacerdotes conduzem os visitantes temerários por uma fenda até aos lagos de fogo que fervem no interior da terra, fazendo-lhes ver o que lá se passa. Durante o caminho o visitante entra em êxtase e sente que se lhe abre a dupla vista. Respirase com custo, a voz estrangula-se na garganta e só por sinais se pode comunicar. Uns recuam a meio do caminho, outros persistem e morrem asfixiados, e, dos poucos que de lá saem vivos, a maior parte

\footnotetext{
${ }^{1} \mathrm{Na}$ língua fenícia, segundo Édouard Schuré, Orfeu seria a junção das palavras aour e raphae, que significam respectivamente luz e cura.
} 
fica louca. Depois de ter visto o que boca alguma deve repetir, eu regressei à gruta e caí em uma letargia profunda. Durante esse sono de morte apareceu-me Eurídice. Ela flutuava em um nimbo, pálida como um raio de luar, e disse-me: 'Por mim tu afrontaste o inferno depois de me ter buscado entre os mortos. Eis-me aqui, acorrendo ao teu apelo. Eu não habito o seio da terra, mas a região do Erebo, o cone de sombra que há entre a Terra e a Lua. É nesse nimbo que eu turbilhono a chorar como tu. Se quiseres libertar-me, salva a Grécia, outorgandolhe a luz. (...) Ouvi apenas como que um som de corda que quebra; depois, uma voz fraca como um sopro, triste como um beijo de adeus, murmurou: - Orfeu!

Ao som dessa voz acordei. Esse nome, proferido por uma alma, transformou o meu ser. Senti passar em mim o estremecimento sagrado em um desejo imenso e o poder de um sobre-humano amor. Eurídice viva ter-me-ia dado a embriaguez da felicidade; Eurídice morta fez-me achar a Verdade. Foi por amor que eu enverguei o vestido de linho, votando-me à grande iniciação e à vida ascética; foi por amor que penetrei na magia e busquei a ciência divina (...). Sondei a morte para nela encontrar a vida e, para além da vida os limbos, as almas, as esferas transparentes, o Éter dos deuses. (ibidem, p. 86 87).

O trecho acima nos revela não só o mítico amor supremo que foi capaz de levar Orfeu a afrontar o inferno, mas também a transformação desse amor por Eurídice em uma missão que o levaria a ser aquele a guiar os gregos a uma morte que significa uma passagem para a vida ascética.

Segundo Schuré, após o sonho com Eurídice, Orfeu lutou até a morte contra Aglaonice e suas bacantes. Entretanto a voz de amor saída de sua "cabeça cadavérica" (ibidem, p. 90) fez com que os seguidores de Hécate fugissem temendo o "verbo órfico" (ibidem, p. 92) que então se fez presente na terra. A partir desse momento, nos templos de Dionísio habitava a estátua de Orfeu, o profeta que trouxe aos gregos a luz da sabedoria eterna.

O texto em questão traz ao mito de Orfeu um olhar religioso que explora a luta do Bem (Orfeu) contra o Mal (a sacerdotisa infernal Aglaonice). Poderíamos dizer que essa luta nos lembra o cristianismo, contudo, devemos acrescentar, Schuré coloca Orfeu como o iniciador não do canto religioso da Igreja católica, mas sim do canto órficodionisíaco a propagar uma luz capaz de pôr término a"o longo circuito das existências tenebrosas" (ibidem, p. 69).

Schuré não traz ao seu texto esse canto órfico mítico. Canto que, por duas vezes, podemos encontrar entoados pelas vozes de Orfeu e Eurídice santarenianos: 
Orfeu - Encontrarás uma fonte à esquerda do átrio de Hades...

Eurídice - ...e ao seu lado um cipreste branco (...)

Orfeu - Encontrarás uma fonte à esquerda do átrio de Hades...

Eurídice - Não te aproximes desta fonte

Orfeu - E encontrarás outra, a fonte do Lago da Memória, de onde flui água fria...

Eurídice - Em frente dela há guardas. Deves dizer:

Orfeu - Sou o filho de Gê e do constelado Ouranos...

Eurídice - A sede ressequiu-me e sinto-me morrer

Orfeu - Sou o filho de Gê e de Ouranos, vós o sabeis...

Eurídice- Venham, dêem-me depressa água fria do Lago da Memória.

Orfeu - Sou o filho de Gê e de Ouranos, todos hão-de sabê-lo!...

Eurídice- E eles próprios te darão a beber água da fonte divina, e depois disso reinarás com os outros heróis. (SANTARENO, p. 61).

Como Santareno ressalta em nota de rodapé, os versos transcritos pertencem à "Petelia, séc. III-IV antes de Cristo" (ibidem, p. 62).

O documento a que Santareno se refere é a lâmina Petelia que foi encontrada no início do século XIX, na Itália, e que pertence atualmente ao acervo do Museu Britânico de Londres. Escrita em grego, a lâmina em questão estava envolta em um cilindro de ouro e pertencia a um túmulo que, segundo os arqueólogos, fora fechado em meados do século IV antes de Cristo. Trazemos a seguir o desenho desse documento histórico:

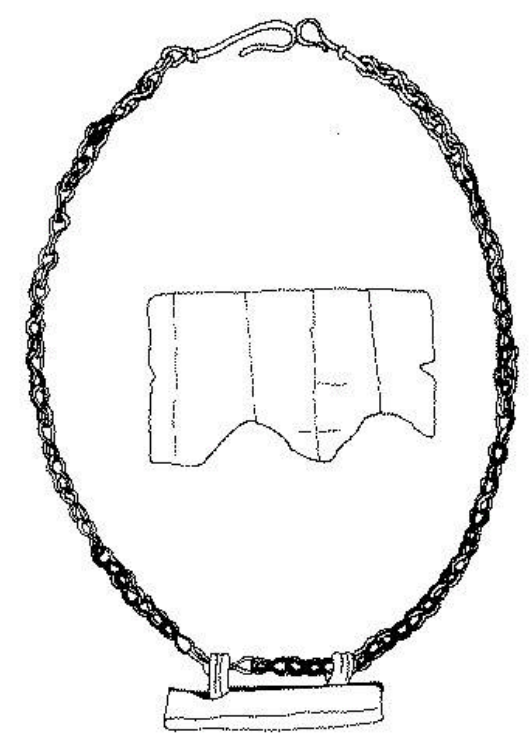




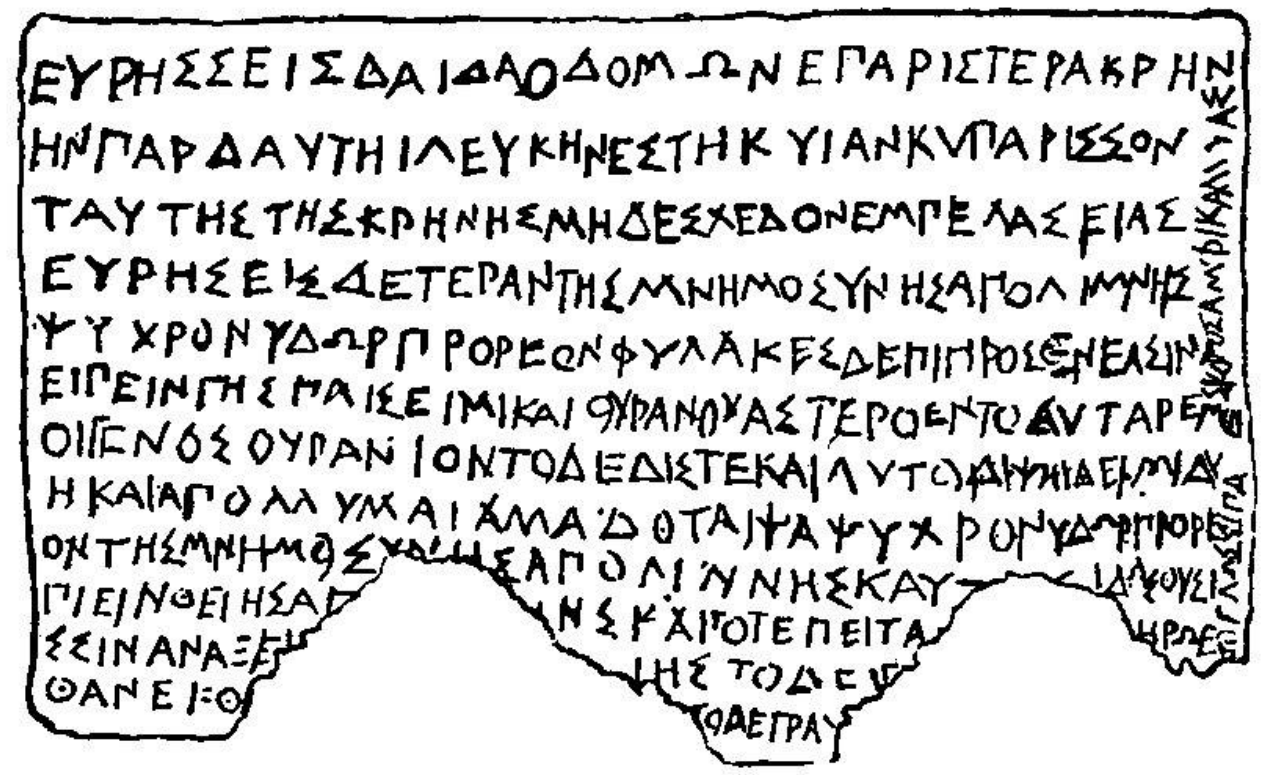

(HARRISON. Acesso em: 23/05/2008.)

Em Los caminos de la muerte: religión, rito e iconografia del paso al más allá em la Grécia antigua., Francisco Diez de Velasco traz a versão para o espanhol das onze lâminas órfico-dionisíacas já publicadas. Segundo esse estudioso, o texto abaixo seria a versão para o espanhol do escrito da lâmina Petelia:

Encontrarás a la izquierda de la morada de Hades una fuente y cerca de ella un blanco y enhiesto ciprés, a esa fuente no te acerques en ningún caso. Encontrarás otra, de la que mana el agua fresca del lago de Memoria, delante de la cual están los guardianes, diles: 'Soy hijo de la Tierra y del Cielo estrellado, pero mi estirpe es celeste y esto lo sabéis también vosotros, agonizo de sed y perezco, dadme prestamente del agua fresca que mana del lago de Memoria', y ellos te permitirán beber de la fuente divina y después reinarás junto con los demás héroes (...) este (...) a punto de morir (...) escrito (...) las tinieblas cubriendo todo alrededor (...) (VELASCO, 10/01/2008).

Ao compararmos as palavras de Orfeu e Eurídice santarenianos com as palavras de Petelia, podemos perceber que o discurso religioso da lâmina foi reproduzido, à exceção das palavras finais, pelos assassinos santarenianos. Como o discurso de Petelia é simbólico, temos que compreender, primeiramente, o significado do documento histórico para entendermos, posteriormente, o motivo que levou o casal de assassinos a declamá-lo. 
Segundo Velasco, as lâminas eram colocadas nos túmulos dos iniciados órficos para que esses pudessem escolher, através das indicações que existem nos escritos, o caminho que os levaria a uma vida ascética. Apesar de utilizarem palavras diferentes, salienta o autor, as onze lâminas trazem o mesmo conteúdo em suas palavras.

Ao iniciado era interdito se aproximar da fonte à esquerda da entrada de Hades, pois se o fizesse, ele se tornaria um criminoso na próxima reencarnação. Além disso, após se guiarem para o caminho da direita, os iniciados deveriam conter a sede que neles habitava, pois só as águas do lago da Memória é que deviam ser bebidas no Hades. Da fonte que brota o lago da Memória, viria o conhecimento das vidas passadas, e os descendentes de Gê e Ouranos - primeiras entidades a formarem o Universo receberiam dos guardas as águas dessa fonte. A sabedoria eterna seria fornecida, desse modo, aos iniciados órficos que, nas vidas futuras, tornar-se-iam, pela sabedoria, heróis.

Na peça santareniana, as palavras de Petelia são ouvidas em dois momentos. No primeiro deles, o casal de amantes, ao lado do corpo de Edward, declama-as. No segundo, entre o som das torturas sofridas pela pequena Ann Gilbert e o veredicto de condenação aplicado ao casal, as palavras de Petelia ecoam nas vozes em off de Orfeu e Eurídice.

Acrescentamos que ao declamarem Petelia ao lado do corpo assassinado de Edward, Eurídice e Orfeu revelam, conforme nos mostram as rubricas, diferentes sentimentos perante a morte. A agonia sentida por Eurídice só é apaziguada pela paixão que ela nutre por Orfeu. O assassino, entretanto, com altivez e frieza, revela que a morte lhe dá um "prazer sádico" (SANTARENO, s.d., p. 62). Ou seja, enquanto Orfeu declama Petelia para mostrar que escolheu ser superior bebendo da fonte que lhe era interdita, Eurídice o faz com o medo de quem é conduzida, por amor, a um caminho de assassinos.

Observamos que os cantos órficos falam de reencarnação, motivo pelo qual a lâmina Petelia estava envolta por um objeto circular no túmulo em que foi encontrada. Acrescentamos ainda que esse retorno à vida não significa, para os órficos, que o ser vivente futuro reproduza indefinidamente suas ações passadas, mas sim a possibilidade de um crescimento espiritual que o levaria à suprema sabedoria dos heróis. Portanto, para os seguidores de Orfeu, a morte é vista como ritual de passagem para vidas que representem uma ascese do espírito. 
Como vimos, Orfeu santareniano recusa essa ascese pregada pelo orfismo e prefere - na morte de Edward, John e Ann - manchar de sangue o cipreste branco. Eurídice santareniana, por sua vez, não pede ao amado a salvação dos homens, mas sim por ele e com ele compactua nos assassinatos cruéis. Sendo assim, as palavras de Petelia indicaram os caminhos a serem seguidos, o casal, contudo, mesmo sabendo que seria condenado na terra pelos seus atos criminosos, preferiu reconstruir sua eterna união não pelo amor do passado, mas sim por uma estranha ascese poética de almas que cultuam o sangue e a perversidade acima de tudo.

Os gritos da pequena Ann pedindo que os assassinos não a machuquem e a levem de volta para casa, mostra-nos a crueldade daqueles que, mesmo guiados ao caminho certo, escolheram ser assassinos.

Os "amantes diabólicos" Orfeu e Eurídice são condenados à prisão perpétua, o que revela que a sociedade em que eles estão inseridos não aprova a escolha do casal.

Acrescentamos que a figura de um Orfeu a escolher o caminho interdito é comum a alguns poetas da literatura moderna. Para comprovar esse fato, trazemos à nossa análise o exemplo de um autor também intertextualizado em $O$ inferno: o dramaturgo e cineasta Jean Cocteau.

No texto dramatúrgico Orphée (1926), Cocteau cria um poeta que abdicou de glorificar o Sol e passou de grande escritor da Trácia a escritor que recebe de um cavalo versos que glorificariam a Lua e que seriam capazes de torná-lo ainda mais famoso. A presença desse estranho na residência dos amantes Orfeu e Eurídice, contudo, faz com que o casal brigue constantemente. Eurídice acusa Orfeu de dar mais atenção ao cavalo que a ela. O poeta, por sua vez, acusa a mulher de ter como amante o vidraceiro Heurtebise. Em uma briga, Orfeu quebra a janela para que o amante de sua esposa possa com ela se encontrar. Heurtebise chega e Orfeu, acusando a esposa, beija o cavalo e diz a esse que voltará ao anoitecer para casa. Sozinha com Heurtebise, Eurídice, olhando para o espelho, confessa seu amor por Orfeu e diz que o ciúme do poeta provém do medo que esse possui de que ela volte ao mundo de Aglaonice. Heurtebise incita Eurídice a matar o cavalo com um cubo de açúcar envenenado. Eurídice, contudo, prefere escrever uma carta à sacerdotisa infernal para pedir-lhe auxílio. Ao lamber o envelope da carta, entretanto, Eurídice morre por um veneno que Aglaonice havia ali colocado. Heurtebise sai em busca da ajuda de Orfeu. A Morte vem buscar Eurídice, 
mas antes de levá-la, dá ao cavalo o açúcar envenenado e o deixa partir. Ao chegar em casa, Orfeu observa a ausência do cavalo e de Eurídice. Ele acusa a mulher de ter deixado o cavalo fugir, contudo, ao vê-la morta dentro do espelho, esquece o animal e pede ajuda a Heurtebise para poder resgatar a amada. Heurtebise diz que Orfeu deve atravessar o espelho para poder resgatar seu amor e entrar, assim, no mundo dos mortos. Orfeu atravessa sua própria imagem. Tempos depois, Eurídice volta do Inferno seguindo Orfeu. Contudo, ele terá que cumprir duas promessas, uma feita a Hécate, outra a Eurídice. À deusa infernal, Orfeu prometera nunca mais unir seu olhar ao de Eurídice. À amada, nunca mais falar com o cavalo. Na mesa com Eurídice e Heurtebise, Orfeu fala das histórias da Lua. Eurídice proíbe Orfeu de falar dessas histórias, ele então dirige a ela, de propósito, seu olhar e Eurídice volta ao Inferno. As bacantes, ofendidas pelo poema que o cavalo ditou a Orfeu, declaram no tribunal que ele é culpado por divulgar uma religião mística proibida: "Madame Eurydice Reviendra Des Enfers" (COCTEAU, 1954, p.137). Orfeu percebe, então, que o cavalo o enganara. Tambores soam, o barulho significa que as bacantes se aproximam para matar Orfeu. Para encontrar a amada, Orfeu se deixa ser destroçado. Eurídice vem buscar a alma de Orfeu. Ocorre um eclipse solar e as bacantes fogem acreditando que o Sol se escondeu para mostrar o desapreço pelo assassínio de um dos seus antigos mensageiros. Os policiais chegam à casa de Orfeu e Eurídice e nesse recinto, encontram Heurtebise e a cabeça de Orfeu. Eurídice volta para buscar Heurtebise e o leva para o outro lado do espelho. A cabeça de Orfeu pede que esse se vá. Os policiais interrogam a cabeça e essa diz se chamar Jean Cocteau. No céu, Eurídice, Orfeu e Heurtebise tomam vinho. Orfeu faz então uma prece a Deus agradecendo por Ele ter-lhe enviado o anjo da guarda Heurtebise, anjo que lhe revelou duas verdades: a do amor capaz de matar o diabo em forma de cavalo e a da poesia que é Deus.

Como imagens pertencentes a um estranho sonho, essa obra de Cocteau revela faces da poesia de Orfeu. Uma delas, a mais conhecida, de que o poeta canta seu amor pela amada. A outra, semelhante aos cantos órficos, de que a poesia de Orfeu é um canto de Deus a revelar a escolha pelo Bem. Uma outra ainda, mostra-nos a cabeça decepada de Orfeu a proclamar-se Jean Cocteau e a cantar que o homem pode escolher ser o poeta que ouve o canto do cavalo e que prefere este e as histórias da Lua à presença de sua Eurídice. 
Acrescentando à frase final de Cocteau em O sangue de um poeta, poderíamos dizer: "O tédio mortal da imortalidade" (COCTEAU, 1930, 55:00) pode fazer com que o poeta faça outras escolhas em suas vidas.

A película ficcional de Cocteau nos leva a concluir que outros poetas trilham o caminho esquerdo de Hades como forma de alcançarem à vida ascética. Acrescentamos que, em $O$ inferno, Bernardo Santareno cita alguns escritos que também na vida real optaram pelo caminho interdito, dentre eles, o próprio Jean Cocteau, Albert Camus, Arthur Rimbaud e André Breton.

Na peça santareniana, Orfeu é poeta pelo nome que carrega, mas também o quer ser porque trouxe ao mundo o seu retrato de arte. Nesse retrato, podemos sublinhar diferentes elementos. Da obra de Cocteau, ele copia a idéia de que o artista deve cultivar em sua obra o que o público mais condena. Contudo, também vendo em Hitler um artista a pregar o ideal de raça ariana, Orfeu copia do füher uma estranha ideologia a ser seguida como sua "Arte poética", aquela que divulga o extermínio de pessoas como uma forma de preservar a pureza da raça. Ao fim e ao cabo, constrói com corpos de uma judia, de um negro e de um homossexual uma poesia condenada pela sociedade, mas que deve ser aceita, segundo ele, como manifestação lírica.

Camus (1919 - 1960) em sua obra O Homem Revoltado (1951), citada por Orfeu santareniano em seu caderno de anotações, defende a idéia de que os artistas modernos surrealistas foram os herdeiros da revolta pensada por Rimbaud (1854 1891). O ensaísta observa, contudo, que alguns artistas surreais, dentre eles André Breton (1896 - 1966), estimulados não só pela obra de Rimbaud, mas também pela vida desse poeta, consideraram que a ação desregrada poderia também ser uma obra poética.

O trecho abaixo retrata essa idéia de que a violência pode ser uma forma de arte:

O surrealismo (...) ousou dizer, e essa é a declaração da qual, desde 1933, André Breton vem se arrependendo, que o ato surrealista mais simples consistia em descer à rua, revólver em punho, e atirar ao acaso no meio da multidão. Para quem recusa qualquer outra determinação que não a do indivíduo e de seu desejo, qualquer primado que não o do inconsciente, isso equivale na verdade a revoltar-se simultaneamente contra a sociedade e a razão. (...) Que significa, efetivamente, essa apologia do assassinato, senão que, em um mundo sem significação e sem honra, só é legítimo o desejo de existir, sob todas as suas formas? O ímpeto da vida, o arrebatamento do inconsciente, o brado do irracional são as únicas verdades puras, que é 
preciso proteger. Tudo aquilo que se opõe ao desejo, e principalmente à sociedade, deve ser destruído sem piedade.(...) Breton, que ainda carrega o estigma dessas declarações, conseguiu fazer o elogio da traição e declarar (o que os surrealistas tentaram provar) que a violência é a única forma adequada de expressão. (CAMUS, 2005, p. 117 - 118).

Observamos que alguns termos do discurso acima nos lembram a poética visionada por Rimbaud. Dentre eles, destacamos o objetivo que tinha o jovem visionário de que a poesia fosse uma forma de expor o desconhecido, aqui denominado de inconsciente. Além disso, assim como Rimbaud pretendia uma poesia a expressar todas as formas de beleza, os surrealistas viram o assassínio como uma forma de arte.

Acerca dessa beleza assassina, acrescentamos ainda um pensamento de Rimbaud frisado por Edmund Wilson em O castelo de Axel (1931).

Rimbaud sempre se afeiçoava a ver-se a si próprio no papel de criminoso. 'Mesmo quando criança', escreve, 'eu admirava o condenado incorrigível, sobre quem se fecham as portas da prisão... Para mim ele tinha mais força que um santo, mais bom senso que um viajante - e a si, apenas a si! Como testemunha de sua própria glória e razão'. (WILSON, 1993, p. 192).

Ou seja, se juntarmos a admiração que Rimbaud sentia pelo criminoso incorrigível à opinião de Breton que o assassínio também seria um ato surrealista, podemos dizer que Orfeu santareniano não seria o único poeta a praticar a violência como arte.

Contudo, devemos salientar que um ponto essencial diferencia a poesia ação construída por Orfeu do ato surrealista observado por Breton. Em Orfeu, as mortes não ocorrem a esmo, mas sim pelo raciocínio cruel de quem escolhe suas vítimas a partir de um pensamento nazista criado por Hitler.

Sendo assim, Orfeu não poderia ser classificado como um poeta surrealista cujos crimes são obras de arte, pois suas ações não foram movidas pela paixão ou pela vontade de cultivar em si os desejos inconscientes, mas sim pela lógica de quem desvirtua ideais que em outrem eram verdadeiros. Ou seja, ao citar Cocteau, Camus, Rimbaud e Breton, Orfeu não estaria vinculado a um projeto de arte moderna, mas sim se servindo desses autores para propagar a idéia de que o assassinato também é uma forma de arte a ser aceita. 
Salientamos ainda que Rimbaud, para Camus, foi um homem a praticar crimes de paixão não na vida desregrada que teve, mas sim na poesia a revelar o inconsciente da alma humana. Além disso, acrescenta o ensaísta, ao perceber que o "surrealismo não era ação, mas ascese e experiência espiritual" (ibidem, p. 121), Breton se arrependeu da declaração em que unia arte ao ato gratuito violento e escolheu, ao invés da vida de Rimbaud, a obra deste poeta visionário.

Os elementos acima nos revelam que Cocteau, Sartre, Breton e Rimbaud trilharam o caminho interdito, mas o compreenderam de forma diferente da entendida por Orfeu santareniano e Hitler. Os primeiros são Orfeu(s) modernos que trazem às suas obras a realidade cruel em que vivemos; os últimos são seres medíocres, pseudopoetas que usam a palavra arte para falsear seus atos violentos.

No julgamento dos “amantes diabólicos de Chester”, Ian Brady e Mira Hinldey foram condenados à prisão perpétua. No julgamento da arte, mostra-nos Santareno, o lirismo moderno pode ter as notas do inebriante canto interdito de Orfeu(s), mas nunca as de canto de extermínio de um falso Orfeu.

\section{REFERÊNCIAS}

BRICOUT, Bernadette (org.). O olhar de Orfeu. São Paulo: Companhia das Letras, 2003. 238p.

CAMUS, Albert. O Homem Revoltado. Rio de Janeiro: Record, 2005 (6 $6^{\text {a }}$ edição). $351 \mathrm{p}$.

COCTEAU, Jean. Le rappel a l'ordre. Paris: Éditions Stock, 1948. 153p.

Le grand écart - suivi de Orpheé. Paris: Librarie Arthème

Fayard, 1954. 128p.

O sangue de um poeta. France: Continental, 1930.

HAMILTON, 1983. A mitologia. Lisboa: Publicações Dom Quixote, 1983. 511 p.

RIMBAUD, Arthur. Uma estadia no inferno. Poemas escolhidos. Carta do vidente. São Paulo: Martin Claret, 2005. 124p.

SANTARENO, Bernardo. O Inferno. Lisboa: Ática, s.d. 227p. 
SHURÉ, Édouard. Os Grandes Iniciados - Orfeu. São Paulo: Martin Claret, 2003. $143 \mathrm{p}$.

WILSON, Edmond. O castelo de Axel. São Paulo: Cultrix, 1993. 224p.

VELASCO, Francisco Diez de. Los caminos de la muerte : religión, rito e iconografía del paso al más allá en la Grecia antigua. Disponível em: www.cervantesvirtual.com Acesso em: 10/01/2008.

HARRISON. Prolegomena to the Study of Greek Religion. sl., sd. p. 573. Disponível em: http://www.theosociety.org Acesso em: 23/05/2008. 